\title{
La provincia en las comunidades autónomas pluriprovinciales, su compatibilidad con la comarca y otras nuevas administraciones ${ }^{1}$
}

\author{
Francisco Delgado Piqueras \\ Catedrático de Derecho Administrativo \\ Universidad de Castilla-La Mancho \\ francisco.delgado@uclm.es
}

\section{SUMARIO}

1. Introducción.

2. Posición de las provincias en el estado autonómico.

2.1. En el momento constituyente y posterior.

2.2. Tras las últimas reformas estatutarias y legales básicas.

2.3. Recapitulación parcial: las provincias como entidades estructurantes de las comunidades autónomas.

3. La opinión de geógrafos, historiadores, lingüistas, economistas.

4. ¿Cómo lo ven los ciudadanos?

5. Propuestas de los partidos políticos y pactos de investidura.

6. Apuntes de la jurisprudencia constitucional reciente.

7. La realidad comarcal de España.

7.1. La organización comarcal de Cataluña.

7.2. La comarcalización de Aragón.

8. Las veguerías en Cataluña.

8.1. Origen estatutario y configuración legal.

8.2. Incidencia de la STC 31/2010, 28 junio.

9. Propuestas finales.

\section{INTRODUCCIÓN}

En el marco del Seminario, esta ponencia aborda el tema territorialmente más extenso, pues afecta a 8 comunidades autónomas que suman 38 provincias. Para no incurrir en redundancias con las anteriores ponencias, daremos por sabido el marco constitucional, estatutario y legal básico, así como la evolución de la jurisprudencia constitucional, dejando solo constancia resumida de todo ello.

Entiendo que, como reza el título, me toca analizar directamente la compatibilidad de la provincia con la comarca y otras nuevas administraciones públicas en las comunidades autónomas pluriprovinciales. Más en concreto, con las veguerías, que suscitan gran interés por su novedad no exenta de polémica.

1 Texto de la ponencia presentada en el Seminario del INAP sobre la Reforma del Estado dedicado a "La organización territorial interna de la Comunidades Autónomas", dirigido por el profesor Santiago Muñoz Machado y celebrado en el Instituto de España, Madrid 30 noviembre 2016. A todos ellos agradezco una vez más su amable invitación. 
No vamos a entrar a examinar las mancomunidades, ni los consorcios ni las entidades metropolitanas y otras entidades instrumentales porque no son figuras nuevas ni generalizables. Tampoco otras muchas entidades que puede haber a lo largo y ancho del país, como el Señorío de Molina o el Valle de Arán, por citar dos que son peculiarísimas.

Hechas las indispensables acotaciones, el orden de exposición empezará por recordar la situación existente y, además del análisis jurídico, echaremos un breve vistazo a lo pueden aportarnos otras ciencias y disciplinas, la opinión ciudadana y las propuestas políticas. Aunque los juristas tenemos nuestro propio método, a menudo formalista, este nunca es ajeno a otras perspectivas. A partir de ahí podremos plantearnos qué se puede hacer en la presente legislatura dentro del marco constitucional vigente ${ }^{2}$.

Como hipótesis, planteamos la posibilidad de reformar los dispuesto en la Ley 7/1985, de 2 abril, “de Bases del Régimen Local (en adelante, LBRL) respecto del gobierno y competencias de las diputaciones provinciales de régimen común, de modo que se introduzca la suficiente flexibilidad como para que puedan acomodarse las comarcas y veguerías, allí donde existan, sin solapamientos ni duplicaciones inconvenientes y, por supuesto, evitando que puedan suponer una trasgresión del bloque de la constitucionalidad ${ }^{3}$. No es que queramos patrocinar la comarcalización del país, sino solo adecuar el marco jurídico básico para que, donde se decida llevar a cabo, lo sea en las mejores condiciones.

No es ciertamente una propuesta original. Como veremos, frente al insatisfactorio estado actual, las opiniones doctrinales se dividen entre los partidarios de reformas legales y los que demandan cambios constitucionales. Pero no he encontrado a ninguno apegado a la regulación vigente. A modo de anticipo, podemos compartir la situación descrita por Pedro ESCRIBANO, quien nota que la regulación uniforme de las diputaciones, reforzada por la interpretación constitucional que incluye la LBRL en el bloque de la constitucionalidad, está dificultando su inserción en la organización territorial de las comunidades autónomas ${ }^{4}$. También aprecia una cierta confusión a propósito de la provincia entre demarcación estatal con entidad local. Lo cual aboca a duplicar las entidades existentes para realizar su proyecto de organización territorial. Sostenida sobre su papel de administración local autónoma, ha sido muy pobre la posibilidad residual de recibir delegaciones y trasferencias tanto del Estado como las comunidades autónomas. Reclama el catedrático sevillano que se ponga fin al pulso entre los distintos niveles territoriales, aceptando que el núcleo indisponible de la autonomía provincial está en el apoyo a los municipios, mientras que el resto puede ser modificado por legislador.

\section{POSICION DE LAS PROVINCIAS EN EL ESTADO AUTONOMICO}

\subsection{En el momento constituyente y posterior}

El estudio de las provincias y diputaciones ocupa un comprensible lugar relevante en la manualística de Derecho Administrativo. En las líneas que siguen seguiremos de cerca al profesor SANCHEZ MORÓN, que es uno de los mejores especialistas sobre la institución 5 .

2 La reubicación de las diputaciones en el nuevo Estado autonómico se ha convertido en un tema recurrente, sobre el que se acumulan análisis y estudios. Uno especialmente amplio y valioso es el Libro Verde realizado por un grupo de expertos dirigido por $\mathrm{Jl}$ MÉMEZ ASENSIO, Los Gobiernos locales intermedios en España, publicado por la Fundación Democracia y Gobierno Local en 2011. Como reza el subtítulo, se trata de un diagnóstico con propuestas para reforzar el valor institucional de las diputaciones provinciales y los demás gobiernos locales intermedios en el Estado autonómico. Su decálogo de sugerentes recomendaciones puede extractarse así: la reforma debe actuar sobre las competencias, la forma de gobierno (sistema electoral y organizativo) y la financiación; la provincia debe ser pieza institucional central de la intermunicipalidad; especialmente para afrontar el minifundismo municipal; hay que reforzar la legitimación democrática de las diputaciones; fortalecer el carácter ejecutivo del gobierno provincial, siendo el pleno el órgano de control, fiscalización y normación; reforzar la eficiencia con un cambio de paradigma organizativo; se le deben atribuir competencias de carácter material o sustantivo, manteniendo las funcionales; vincular su financiación a las competencias, para mejorar su suficiencia y autonomía; protagonismo de las diputaciones y demás gobiernos locales intermedios en la reforma de la legislación básica y necesidad de alcanzar un consenso entre las fuerzas políticas para afrontar estas reformas.

3 Claro que a otro nivel, de reforma constitucional, como propugnan muchos autores, se pueden proponer cambios más ambiciosos. Así, Tomás FONT ("Los retos actuales del Gobierno local: repolitización, diversificación, interiorización", en el libro coordinado por J. M. ${ }^{a}$ BAÑO LEÓN, Memorial para la reforma del Estado, tomo II, págs. 1907 y ss.) considera que, en el contexto de la reforma constitucional, se puede plantear una mayor interiorización del nivel local, por las vías de una mayor densidad estatutaria del gobierno local (organización, competencias, etc.), mayores competencias autonómicas también sobre financiación local, reformando el 149 CE si fuese necesario, y más participación del gobierno local en las instituciones autonómicas. En resumen, es partidario de que una reforma constitucional atribuya a los estatutos la función de regular la relación entre comunidades autónomas y administraciones locales, en vez de que sea la propia Constitución la que lo haga. También de que los estatutos abran el campo al legislador autonómico sobre elecciones locales, estableciendo otros órganos representativos diversos, pero que no afecten a los ayuntamientos, alcaldes y concejales y su función.

4 ESCRIBANO COLLADO, P., "Provincias y diputaciones: una polémica sin proyecto institucional", en el libro coordinado por J. M. ${ }^{a}$ BAÑo LEÓN, Memorial para la reforma del Estado, tomo II, págs. 1995 y ss.

5 SÁNCHEZ MORÓN, M., Derecho Administrativo. Parte General, 12. ${ }^{a}$ ed., Tecnos, 2016. 
En apretada síntesis, recordemos que conforme al $137 \mathrm{CE}$, el Estado se organiza territorialmente en municipios, provincias y comunidades autónomas que gozan de autonomía. En virtud del art. 140 CE la provincia es una entidad local, por agrupación de municipios y división territorial del Estado. Su alteración requiere ley orgánica. Y su gobierno y administración corresponde a las diputaciones y otras corporaciones representativas ${ }^{6}$. El art. 141.3 CE admite que se pueden crear agrupaciones de municipios distintos de la provincia y el 152.3 CE que los estatutos de autonomía pueden establecer agrupaciones de municipios limítrofes como circunscripciones territoriales propias. Es en este marco donde deben encontrar acomodo, aunque no cuenten con una alusión explícita, las comarcas y las veguerías.

La evolución desde entonces ha sido ciertamente curiosa, pues tuvieron un papel preponderante en el primer momento, al ser el sujeto constituyente de las comunidades autónomas (art. 143 CE), de casi todas ellas: Andalucía, Aragón, Castilla-La Mancha, Castilla y León, etc. salvo en aquellas que habían gozado históricamente de un reconocimiento previo (art. $151 \mathrm{CE}$ ).

Si bien la STC 76/1983, de 5 de agosto, estimó buena parte de los recursos contra el Proyecto de Ley Orgánica Armonizadora del Proceso autonómico (LOAPA), las previsiones ya se habían incorporado a los estatutos andaluz, aragonés, castellano-leonés, y otros, que asumieron las diputaciones como su administración periférica ordinaria, idóneas para recibir trasferencias, delegaciones y la gestión ordinaria de los servicios autonómicos, bajo la dirección del gobierno regional. Todavía reza así en el art. 30.3 del Estatuto de Autonomía de Castilla-La Mancha (L.O. 9/1982, de 10 de agosto), cuyas previsiones están sin embargo inéditas ${ }^{7}$. Salvo error, solo el Estatuto de Galicia dice expresamente que la Xunta ejercerá sus funciones a través de sus órganos y entes propios, aunque podrá delegar en las provincias (art. 41 LO 1/1981, de 6 de abril).

Pero una vez consolidadas las comunidades autónomas, las diputaciones pasaron a estar en el punto de mira de algunas de ellas y ser vistas como elemento centralizador del Estado unitario y uniforme ${ }^{8}$, cuando en realidad su origen es la Constitución de Cádiz 1812 y no los Decretos de Nueva Planta de Felipe V en 1714 (por más que estos suprimieron las veguerías). Y su propósito fue introducir racionalidad y control sobre los municipios.

Abundan, en ese sentido, las leyes de coordinación, que someten actuaciones de las diputaciones al superior criterio de la comunidad autónoma en materias de interés regional ${ }^{9}$. Hoy casi todas las comunidades se arrogan esta coordinación, en especial de planes de obras y servicios ${ }^{10}$. Con carácter general, los arts. 10 y 59 LBRL admiten que, en el ejercicio de sus competencias, el Estado y las comunidades autónomas coordinen de modo forzoso las diputaciones con planes sectoriales que fijen prioridades, objetivos, límites, controles, etc. ". Claro que habría que saber hasta qué punto se practica esa coordinación. Como señala el profesor Miguel BELTRAN en el trabajo antes citado, la Ley de Castilla-La Mancha 2/1991, de 14 de marzo, "de coordinación de Diputaciones" no se ha aplicado nunca. Seguramente no sea la única región donde sucede.

6 Según explicó GARCIA DE ENTERRÍA (La provincia en el sistema constitucional, Civitas, 1991, pág. 6), el reconocimiento constitucional de la provincia fue un mecanismo de seguridad, confiando en algo que venía funcionando ciento cincuenta años, ante la inseguridad de lo que sucedería con las comunidades autónomas, pero permitiendo su sustitución paulatina.

7 Así lo ha constatado recientemente Miguel BELTRAN DE FELIPE en el capítulo “La Administración Regional”, dentro del libro del que es coordinador, Derecho Público de Castilla-La Mancha, lustel, 2016, pág. 151 y ss.

8 Un primer embate fue la Ley catalana 6/1980, de 17 de diciembre, "sobre transferencia urgente y plena de las diputaciones catalanas a la Generalidad", anulada parcialmente por sentencia 32/1981, de 28 de julio, por violar la garantía institucional de la provincia respecto del legislador sectorial estatal y autonómico.

9 Se pueden poner de ejemplo la Ley $2 / 1983$, de 4 de octubre, "por la que se declaran de interés general para la Comunidad Valenciana determinadas funciones propias de las Diputaciones", que recibió el visto bueno en la STC 27/1987, de 27 febrero, salvo el carácter suspensivo del requerimiento de rectificación. Y la Ley 23/1987, de 23 de diciembre, "por la que se establecen los criterios de financiación del Plan único de obras y servicios de Cataluña a las Bases para la selección, distribución y financiación de las obras y servicios a incluir en el mismo", que también fue aceptada por la STC 109/1998, de 21 mayo, salvo la absorción de todo el dinero que las diputaciones destinen a cooperación.

10 Así, el art. 74 de la Ley 7/1999, de 9 de abril, “de Administración Local de Aragón” y el análogo de la Ley 5/1990, de 30 de noviembre, "de relaciones interadministrativas entre las Diputaciones Provinciales de Badajoz y Cáceres y la Comunidad Autónoma de Extremadura".

11 Igualmente pueden controlar la legalidad de sus actos impugnándolos ante los tribunales (art 65), sustituirlas si incumplen teniendo medios y afectando a las competencias superiores (art. 60) y suspender acuerdos que atenten gravemente contra España (art. 67) y hasta disolver por gestión inconstitucional (art. 61). Además, hay controles para decisiones concretas como monopolizar servicios (art. 86.3), enajenar inmuebles (art. 79.1), someter a consulta popular (art. 71) o emitir deuda (art 54 Real Decreto Legislativo 2/2004, de 5 de marzo, "por el que se aprueba el texto refundido de la Ley Reguladora de las Haciendas Locales"). 
Aunque son escasos, algunos ejemplos hay en la legislación sectorial autonómica que delegan o atribuyen competencias a las diputaciones. Como muestra, la Ley 2/2011, "de Turismo de Extremadura" ${ }^{12}$. O la Ley 2/2014, de 8 de mayo, "de museos de Castilla-La Mancha" ${ }^{13}$.

\subsection{Tras las últimas reformas estatutarias y legales basicas}

En las pasadas reformas estatutarias también se reprodujo el debate sobre la interiorización de las entidades locales en la estructura de las comunidades autónomas. La ampliación de los contenidos estatutarios en la materia responde a la pasividad del Estado en acometer reformas, criticada por algunos autores como Luis ORTEGA y Luciano PAREJO, para quienes las posibles insuficiencias deben ser resueltas mediante una interpretación superadora e integrada de los arts. 137 y 140 a $142 \mathrm{CE}$, entendiendo que provincia y municipio son un mismo y único poder local articulado en dos instancias ${ }^{14}$.

En general, los estatutos nuevos mencionan a la provincia como parte de la estructura territorial autonómica, dentro de las bases que fije el Estado. El Estatuto de la Comunidad Valenciana (modificado por LO 1/2006, de 10 de abril) llega a considerar a la diputaciones como instituciones de la Generalitat (art. 66). Sólo el nuevo Estatuto de Cataluña no las menciona más que para referirse a su sustitución por las veguerías, a través del cauce previsto en el art 141 CE; cuando el Estatuto de 1979 no las mencionaba, pero sí las aceptaba.

En este debate, los autores más municipalistas defienden la diputación como garantía del poder municipal frente al nuevo poder autonómico. En ese sentido, el profesor Luciano PAREJO valora el hecho de que los gobiernos de ayuntamientos y diputaciones tienen legitimación democrática directa, es decir, canalizan la participación ciudadana en cargos públicos (art. $23 \mathrm{CE}$ ). A su juicio, las comunidades autónomas no pueden pretender una completa interiorización de la administración local como si fuera solo suya. Y sostiene que las reformas generales la debe hacer el Estado ${ }^{15}$.

Cuenta esta postura con el importante respaldo del Tribunal Constitucional, cuyas sentencias mantienen incólume a la provincia como parte indisponible del Estado, derivada de la naturaleza bifronte del régimen local y su garantía institucional, dentro de ser el régimen local competencia compartida. Aunque no es ni mucho menos unánime.

Un autor tan significado por sus contribuciones a las reformas constitucionales que demanda la situación presente de España como Santiago MUÑOZ MACHADO aprecia un error de partida en el llamado «carácter bifronte» del régimen local español, ya que en los estados descentralizados es un tema interno de los estados, länder, etc. A su juicio, la administración local debería ser asunto intraautónomico, cuyo estatutos serían los mejores

12 Artículo 5: Competencias turísticas de las Diputaciones Provinciales.

«1. Corresponden a las Diputaciones Provinciales, sin perjuicio de las competencias establecidas por la legislación de régimen local, las siguientes atribuciones en materia de turismo:

a) La creación, conservación, mejora y protección de los recursos turísticos de la provincia, así como la gestión de los recursos turísticos de titularidad provincial.

b) La gestión de las oficinas provinciales de turismo y aquellas derivadas por acuerdos con la Administración Autonómica.

c) La prestación de la asistencia necesaria a los municipios, a las Mancomunidades y a las Zonas de Desarrollo Sostenible para la conservación de los recursos turísticos y su efectivo disfrute.

d) El asesoramiento y apoyo técnico a los entes locales de su ámbito territorial en cualquier aspecto que mejore su competitividad turística.

e) La participación en el proceso de elaboración de los planes de ordenación y promoción turística de Extremadura.

f) La colaboración con la Administración Estatal, Autonómica y Local y otras entidades locales para la promoción de zonas y recursos comunes.

g) La colaboración con el sector privado y social en cuantas actuaciones fueren de interés para el fomento y promoción de la actividad turística. En particular, el asesoramiento técnico a las pequeñas y medianas empresas para la puesta en funcionamiento de nuevas actividades turísticas.

2. Las Diputaciones Provinciales ejercerán sus competencias turísticas en colaboración con la Consejería competente en materia de turismo y con las demás Administraciones Turísticas de su ámbito territorial.»

13 Artículo 43. Competencias de las Entidades Locales.

«Las Entidades Locales de Castilla-La Mancha que sean titulares de instituciones museísticas, además de las atribuciones que les correspondan al amparo de la normativa reguladora del régimen local, desarrollarán las siguientes funciones:

a) Gestionar, instruir, reglamentar y mantener las instituciones museísticas de las que sean titulares en los términos que establece esta ley.

b) Fomentar y apoyar a las instituciones museísticas, cualquiera que sea su titularidad, que radiquen en su ámbito territorial.

c) Informar a la administración competente en materia de museos sobre la creación de instituciones museísticas que radiquen en su ámbito territorial, así como de la existencia de situaciones de riesgo o que puedan poner en riesgo el patrimonio cultural conservado en las instituciones museísticas de su competencia.»

14 ORTEGA ÁLVAREZ, L., "Régimen local y Estatutos de Autonomía”, Revista de Estudios de la Administración Local y Autonómica (REALA), núm. 300-301, 2006, págs. 35 y ss.; PAREJO ALFONSO, L., “Autonomía Local, Régimen Local Básico y Reformas Estatutarias”, Revista de Estudios de la Administración Local y Autonómica (REALA), núm. 309, 2009, págs. 9 y ss.

15 PAREJO ALFONSO, L., "Reflexiones en torno al Gobierno y Administración locales y su racionalización para garantizar su sostenibilidad”, en el libro coordinado por BAÑO LEÓN, Memorial para la reforma del Estado, tomo II, págs. 1899 y ss. 
garantes de la autonomía local frente al legislador. También disiente de la doctrina constitucional y cree que en la Constitución la garantía institucional no impide que la regulación de las provincias evolucione ni la supresión de alguna provincia mediante ley orgánica, que a su juicio no sería un cambio sustancial. En todo caso, coincide con los demás autores en que es poco racional multiplicar los niveles organizativos, creando nuevos a la vez que se mantienen los existentes ${ }^{16}$.

Como vamos a ver después, las diputaciones quedan entre la espada y la pared, como víctima propiciatoria en las propuestas de reducción del Estado, acosadas por diversos frentes. Uno es el programa nacionalista en Cataluña, abiertamente contrario, que apuesta por una entidad nueva: la veguería ${ }^{17}$. Otro es la difícil visualización de los servicios que presta, que además suelen salir caros pues soportan altos gastos de funcionamiento. Con la crisis económica y los escándalos se agudizan las críticas. E incluso algunos partidos nacionales proponen su supresión abiertamente.

Sorprendentemente, la mayoría del Partido Popular al aprobar la Ley 27/2013, “de racionalización y sostenibilidad de la Administracion Local”, pretendió reforzar la posición que las diputaciones ya tenían en LBRL de 1985. En esa dirección, mantiene que la provincia es una entidad local determinada por la agrupación de municipios, con personalidad jurídica propia y plena capacidad para el cumplimiento de sus fines (art. 31), cuyos fines son garantizar los principios de solidaridad y equilibrio intermunicipales, asegurar la prestación de los servicios de competencia municipal y participar en la coordinación de la administración local con la de la comunidad autónoma y del Estado.

Uno de los efectos colaterales de la LRSAL, a decir de la profesora Catalina ESCUIN, es precisamente que ha desmontado el mito de que el Estado era el garante de la autonomía local frente a las comunidades autónomas, pues les quita competencias a los ayuntamientos para darlas a las diputaciones y comunidades ${ }^{18}$. Coincide con muchos autores en prever el incumplimiento de dicha Ley, antes del pronunciamiento del Tribunal Constitucional. Por un lado, la legislación sectorial autonómica ha tratado de desactivar la redistribución. De otro, muchos de los servicios que se consideran el núcleo de la autonomía local (basuras, limpieza, aguas, etc.) están en manos de concesionarios privados. Al igual que otros autores, es partidaria de replantearse el modelo bifronte y que sean las comunidades autónomas las que afronten la diversidad mediante la reforma de la planta local, de las redes de cooperación municipal, de las comarcas, las diputaciones y otras.

Como señala el profesor PAREJO ALFONSO en el trabajo antes citado, una alternativa al planteamiento de la LRSAL hubiera sido la comarcalización, redistribuyendo competencias, en vez de potenciar el nivel provincial y reasignar algunas competencias municipales a las comunidades autónomas mediante fórmulas muy complejas unas y ajenas a su decisión final que no garantizan su aplicación, por lo que pueden quedar en nada. También echa en falta un cambio en la forma de elección de los diputados provinciales.

Desde otra perspectiva también crítica, Federico CASTILLO entiende que la solución de la LRSAL obedece a la idea instalada en la clase política de que no hay consenso para modificar el Titulo VIII de la CE, a pesar de que lo demanda con urgencia. En línea con otros juristas, este autor apoya la diversificación del espacio supramunicipal en las comunidades autónomas y rechaza el planteamiento uniforme de que en todas las provincias haya diputaciones obligatoriamente, sin perjuicio de que puedan subsistir como demarcación electoral estatal. El catedrático de Granada apuesta abiertamente por la llamada interiorización en el ámbito autonómico porque así se atendería a la diversidad existente y, en ese sentido, permitiría modelos comarcales con una correlativa reordenación de las competencias municipales, separando la prestación de los servicios de lo que es la participación en asuntos que afecten a estas entidades ${ }^{19}$.

Finalmente, Pedro ESCRIBANO coincide en que la LRSAL no era la respuesta que esperaba la doctrina mayoritaria, pues no modifica la elección indirecta de las autoridades provinciales ni la irresponsabilidad política en que

16 MUÑOZ MACHADO, S., Tratado de Derecho Administrativo y de Derecho Público General, tomo XI. Instituciones Autonómicas y Locales, Agencia Estatal Boletín Oficial del Estado, Madrid, 2015, pág. 147 y ss.

17 Señala Tomás FONT -op. cit., pág. 1932-, la provincia sufre dinámicas contrapuestas: el respaldo por la LRSAL y la sustitución por veguerías en Cataluña. Pero, a su juicio, la CE ofrece una diversificación, pues admite que las provincias pueden ser gobernadas por las diputaciones y también por otras corporaciones representativas (art. 141); de hecho, hoy tenemos cabildos insulares y diputaciones forales con gobiernos directamente elegidos y otras uniprovinciales donde no hay poder intermedio local. Además, el art. 143 CE permite otras agrupaciones de municipios distintas de la provincia, que serían las comarcas en distintas comunidades autónomas. Ello debería permitir flexibilizar la normativa para superar rigideces y encontrar soluciones adaptadas a realidades tan distintas como puedan ser los municipios de ínfima población y otros de carácter metropolitano, etc.

18 ESCUIN PALOP, C., “Algunas reflexiones sobre la Administración local”, en el libro coordinado por BAÑO LEÓN, Memorial para la reforma del Estado, tomo II, págs. 1983 y ss.

19 CASTILLO BLANCO, F., "La reforma de los Gobierno locales en España: ¿una oportunidad perdida para lograr una planta local competitiva y sostenible?”, en el libro coordinado por J. M. ${ }^{a}$ BAÑO LEÓN, Memorial para la reforma del Estado, tomo II, págs. 1947 y ss. 
se mueve, tampoco corrige clientelismo ni la opacidad ni identifica bien los intereses a que se debe; de modo que solo refuerza su control sobre ayuntamientos ${ }^{20}$. Postula una reforma constitucional que elimine la provincia como entidad local necesaria y permita fórmulas alternativas en cada comunidad autónoma.

Podemos concluir, en suma, que en el punto que aquí tratamos la LRSAL ha generado muchas más críticas que adhesiones. Se puede decir que las reformas de fondo siguen pendientes. Empero creo que valdría la pena intentarlo con un cambio a nivel de legislación básica, sin necesidad de esperar cruzados de brazos a una reforma constitucional que no se vislumbra en el horizonte, pues los cambios que se proponen con mayor consenso son posibles con la vigente Carta Magna.

\subsection{Recapitulacion parcial: Las provincias como entidades estructurantes de las comunidades autonomas}

Como sabemos, la provincia es un ámbito territorial que sirve para una pluralidad de efectos, alcanzando así diferentes significados políticos y jurídicos.

En un breve repaso, y contando con lo que se ha expuesto en las otras ponencias, recordaremos que todas las provincias son constitucionalmente divisiones periféricas de la administración general del Estado (art. 137 CE). Y circunscripción electoral para las Cortes Generales (art. 68.2 CE).

En 8 comunidades autónomas pluriprovinciales (Galicia, Castilla y León, Aragón, Cataluña, Comunidad Valenciana, Castilla-La Mancha, Extremadura y Andalucía), las 38 provincias que llamamos de régimen común son a la vez circunscripción electoral para los parlamentos regionales. También son la división periférica autonómica, salvo para la Generalidad de Cataluña. Finalmente, estas provincias también son entidades locales supramunicipales, cuyo gobierno corresponde a las diputaciones provinciales.

Pero en 6 comunidades autónomas uniprovinciales (Asturias, Cantabria, Navarra, La Rioja, Madrid, Murcia) ya no existen las diputaciones provinciales, al haber sido sustituidas por los gobiernos y administraciones regionales. En los territorios históricos vascos, el gobierno de las otrora provincias corresponde a las diputaciones forales. En las dos provincias canarias, el gobierno supralocal está en manos de los cabildos insulares y las mancomunidades provinciales interinsulares. Y en las Islas Baleares el gobierno supramunicipal son los consejos insulares ${ }^{21}$.

A juzgar por lo expuesto en las demás ponencias del Seminario, todo indica que en este segundo grupo de comunidades autónomas nadie echa de menos a las diputaciones provinciales; por lo que podemos pasar a ver qué cambios han introducido «ad intra» las primeras.

Todos los estatutos de autonomía de las comunidades pluriprovinciales prevén la posibilidad de crear comarcas, sea como entidad local supramunicipal, sea también como división periférica. Pero sólo dos -Aragón y Cataluña- han llevado a cabo una comarcalización general. Como después veremos, la comarca de Aragón es una nueva administración local, aparte y superpuesta a las diputaciones provinciales. En Cataluña, la Generalidad mantiene desde el principio un pulso frontal con el Estado a cuenta de las diputaciones, con evolutivos planteamientos: absorberlas, coordinarlas, desaparecerlas, sustituirlas. Con el telón de fondo del debate nacionalista, la implantación primero de las comarcas y sobre todo de las veguerías ha resultado ciertamente más conflictivo.

Caso aparte es el de Castilla y León y la Ley 1/1991, de 14 de marzo, "por la que se crea y regula la comarca de El Bierzo". Se trata de una singularidad que no podemos abordar ahora.

Dicho esto, son varios los problemas que preocupan a los estudiosos, empezando por la propia situación de las diputaciones provinciales y, claro está, su relación con los nuevos entes territoriales que se añaden y se superponen, disputando a los existentes sus atribuciones, pues su implantación se lleva a cabo sin una adaptación competencial ni una reestructuración administrativa. Esta acumulación de administraciones públicas sobre un mismo espacio territorial, como si de las famosas matrioskas rusas se tratase, incrementa la complejidad competencial y

20 ESCRIBANO COLLADO, P., “Provincias y diputaciones: una polémica sin proyecto constitucional”, en el libro coordinado por BAÑO LEÓN, Memorial para la reforma del Estado, tomo II, págs. 2013 y ss.

21 Explica Manuel SARMIENTO ("Dos cuestiones polémicas sobre la reestructuración del Estado: mapa autonómico y papel de las Diputaciones provinciales”, en el libro coordinado por BAÑO LEÓN, Memorial para la reforma del Estado, tomo II, págs. 2031 y ss.) que los cabildos insulares de Canarias no son equiparables a diputaciones, pues además de entidades locales son instituciones descentralizadas de la comunidad autónoma, cuyo estatuto regula sus aspectos esenciales, protegiéndolas frente a las bases estatales. Las mancomunidades interinsulares canarias son solo órganos representativos que expresan intereses provinciales, pero no gobiernan ni administran la provincia. Lo mismo sucede con los consejos insulares de las Baleares. Y la STC 132/2012, de 19 de junio, al resolver el recurso de inconstitucionalidad contra la Ley de las Illes Balears 8/2000, de 27 de octubre, “de consejos insulares”, los ha validado al amparo del hecho diferencial contemplado en el 141.4 CE. 
el coste de los servicios, hasta el punto de que muchos dudan de que sea racional. Las preguntas más comunes son si todo este andamiaje mejora los servicios que reciben los ciudadanos, si es económicamente sostenible y si no se podría simplificar. Los juristas se cuestionan también si es constitucionalmente factible.

\section{LA OPINIÓN DE GEÓGRAFOS, HISTORIADORES, LINGUISTAS, ECONOMISTAS}

La opinión de otras disciplinas acerca de las comarcas (y las veguerías, en su caso) también importa, ya que los estatutos de autonomía y la legislación local suelen señalar que estas se configuran como la agrupación de municipios limítrofes con características geográficas, económicas, sociales e históricas afines.

Amén de su origen histórico, la Ley catalana 30/2010, de 3 de agosto, requiere que la creación de las veguerías incluya una memoria que justifique sus motivos y su oportunidad con un estudio de la viabilidad económica y del impacto geográfico, demográfico, económico y social.

Sin embargo, si recorremos los libros, enciclopedias, mapas y demás fuentes al uso difícilmente encontramos coincidencia entre las distintas aproximaciones señaladas ni, dentro de cada una de ellas, hay consenso entre los autores sobre las regiones, provincias y comarcas naturales, lingüísticas, históricas, etc que deban ser. Quiere decirse que son factores a tener en cuenta, y dichas opiniones no son baladíes, pero tampoco dan una solución definitiva que pueda elevarse a una dimensión jurídica.

\section{4. ¿CÓMO LO VEN LOS CIUDADANOS?}

No es fácil saber a ciencia cierta qué piensan los ciudadanos en general sobre las diputaciones o las provincias. Este tipo de cuestionamientos no entran en las encuestas que periódicamente realiza el Centro de Estudios Sociológicos, cuando pregunta sobre el nivel de preocupación en torno al terrorismo, el paro, la corrupción y otros problemas.

Podemos aventurarnos a pensar que en las capitales de provincia, ciudades grandes y comunidades autónomas donde han desaparecido las diputaciones provinciales son desconocidas. $\mathrm{O}$, al menos, difícilmente identificables, por lo que poco pueden ser valoradas ni apreciadas. Si acaso, por algún teatro, algún asilo y otras sedes de servicios provinciales; los mayores recodarán también los manicomios, en Madrid la tradicional corrida de la Beneficencia,...

Pero, en general, las diputaciones son la víctima fácil del discurso anti-administración y anti-política. Los palacios provinciales son vistos como lugares llenos de políticos, asesores y funcionarios cuyos sueldos y condiciones de trabajo en general son la envidia del resto. Si salen en los medios nacionales de comunicación es por hacer obras faraónicas caprichosas como, por ejemplo, aeropuertos para pasear, no más acertados que el de Corvera a costa de la comunidad autónoma de Murcia, el de Ciudad Real promovido por la iniciativa privada y muchos de los que gestiona AENA. Salvo que salgan en los sucesos o den motivo de escándalo, sus dirigentes son grandes desconocidos.

Las diputaciones se hacen más visibles en los pequeños pueblos, que es donde los medios provinciales prestan más servicios, muchos de ellos indispensables, cuando no son los únicos que reciben los vecinos. Son las máquinas de la diputación las que reparan los caminos rurales, son los bomberos de la diputación los que apagan el fuego, son los servicios sociales provinciales los que asisten a los ancianos. Son los presupuestos provinciales los que sirven para financiar pequeñas obras de arreglo de calles y demás que dan empleo a la mano de obra local.

Aquí son importantes, como digo, porque prestan servicios, ejecutan obras y dan trabajo cuando los ayuntamientos no pueden. Para los alcaldes y concejales las diputaciones son interlocutores más accesibles. Diputados y presidentes provinciales tienen presencia regular en los pueblos. Ergo son estos vecinos los que pueden formarse una mejor opinión al respecto, que pocas veces trasciende.

\section{PROPUESTAS DE LOS PARTIDOS POLITICOS Y PACTOS DE INVESTIDURA}

Las diputaciones, como cualquier otra instancia de poder, es para los partidos políticos una fuente de cargos públicos, con posibilidad de nombrar asesores, gerentes, funcionarios,.... Muy importante es el manejo de los presupuestos y, en definitiva, de unos medios para poner en pie sus políticas.

No es extraño que sus principales defensores estén entre quienes gobiernan o han gobernado estas instituciones. En cambio, gustan menos cuando las ocupa el partido contrario u otra facción del mismo partido, pues son vistas como un contrapoder. 
Sin queramos decir que hay una correlación determinante e interesada, esto se refleja en los mensajes y propuestas que han ofrecido en las pasadas elecciones generales ${ }^{22}$. Muy en síntesis, el Partido Popular defiende la continuidad de las diputaciones, al considerarlas necesarias para dar servicios a los pequeños municipios. Afirma que la red de diputados provinciales asegura la cercanía a esas localidades. Y destaca que son eficientes, pues no están endeudadas.

El Partido Socialista Obrero Español enfatiza el origen democrático, aunque indirecto, de las diputaciones. Las defiende porque, a su juicio, garantizan la autonomía de los ayuntamientos respecto de otros niveles superiores de gobierno. Y critica que el Gobierno popular haya utilizado la Ley 27/2013, de 27 diciembre, "de racionalización y sostenibilidad de la Administracion Local" (en adelante LRSAL) para reducir el Estado del Bienestar a ese nivel ${ }^{23}$.

Podemos las considera un instrumento caciquil y clientelar, alejado de los ciudadanos e irresponsables, pues no rinden cuentas electoralmente; de ahí que también sean caldo de cultivo para la corrupción. Y propone que sean sustituidas por las comunidades autónomas.

Ciudadanos critica sobre todo que sus competencias son difusas, su gasto de funcionamiento excesivo y, en general, arbitrario. $Y$ propone sustituirlas por consejos provinciales de alcaldes.

Esquerra Republicana de Cataluña las tiene por una entidad centralista, o al menos heredera del centralismo y contraria a sus instituciones históricas, por lo que quiere sustituirlas por las veguerías.

Finalmente, el Partido Nacionalista Vasco se muestra conforme con las diputaciones forales, en las que actualmente gobierna.

Muchas de estas críticas son ampliamente compartidas por la doctrina científica, en términos a veces incluso más severos ${ }^{24}$.

Como experiencia novedosa cabe dejar constancia de los pactos postectorales. Así, en el infructuoso pacto de junio de 2016 entre PSOE y Ciudadanos se acordó expresamente la supresión de las diputaciones de régimen común y su sustitución por consejos provinciales de alcaldes que atiendan al servicio de los municipios menores de 20.000 habitantes. Este punto del pacto fue motivo de atención preferente en la prensa, que mostró su preocupación por el coste de la institución en relación con los servicios que presta ${ }^{25}$.

22 Julio González García recoge en su blog el video del Seminario organizado en Segovia el pasado 2 de noviembre de 2016 por la Fundación Valsaín para la Promoción y Defensa de los Valores Democráticos sobre la conveniencia o no de mantener las Diputaciones y las posibles líneas de modificación de su régimen actual. En el mismo mantuvieron un interesante debate representantes de los cuatro grandes partidos parlamentarios: PP, PSOE, Podemos y Ciudadanos. Contó también con tres profesores especialistas en esta materia: Alejandro Nieto, que resumió la historia de las diputaciones en el siglo XIX; Maria Angeles González Bustos se encargó de explicar cómo ha afectado a la diputaciones la LRSAL y Carmen Agoués el modelo vasco de las Diputaciones.

Como director del Seminario, el profesor González García extrajo en sus conclusiones: «De entrada, hay que señalar la dificultad constitucional que supondría la modificación de las bases constitucionales de las Diputaciones, teniendo en cuenta la composición de las cámaras y la mayoría con que cuenta el PP. No obstante, si esto puede eliminar el debate sobre su eliminación, no hace improcedente que se pueda abrir un debate para clarificar y mejorar su régimen jurídico. De este modo, sería conveniente que en esta nueva legislatura que ha empezado ahora pudiera debatirse sobre los siguientes aspectos:

En primer lado, la forma de elección de los diputados provinciales, superando el sistema actual de sufragio indirecto y pasar a ser elegidos por la población de forma directa, con la presentación de programas electorales. De igual manera, habría que conectar el cuerpo electoral con los destinatarios de la actividad de la Diputación, que no son más que los municipios de menos de 20.000 habitantes.

En segundo lugar, sería conveniente abordar el problema de la relación que existe entre población y aportaciones del Estado. Como se señaló en el seminario, no resulta demasiado razonable que en el cómputo de las aportaciones del Estado entre la población completa de la provincia, cuando la labor de la Diputación se refiere sólo a una parte de ella. Esto hace que la Diputación de Barcelona tenga un presupuesto de 600 millones de euros cuando la de Segovia tiene sólo 60, a pesar de que la población a la que se dirige su actuación es equivalente.

En tercer lugar, habría que mejorar los mecanismos de rendición de cuentas ante la ciudadanía, teniendo en cuenta los presupuestos que manejan y la importancia que tienen para una parte considerable de la población española, que vive en municipios afectados por su actividad.» http://www.globalpoliticsandlaw.net/diputaciones-provinciales-a-debate/

23 De los trabajos dedicados a la incidencia de esta Ley sobre las diputaciones, podemos destacar: Rafael JIMÉNEZ ASENSIO, “La posición institucional de las Diputaciones provinciales a partir de la Ley de Racionalización y Sostenibilidad de la Administración Local”, Diario de Derecho Municipal, lustel, 13-1-2014, y los incluidos en el libro dirigido por Manuel DOMINGO ZABALLOS, Reforma del Régimen «Local», Thomson Reuters Aranzadi, 2014.

24 Así, FONT I LLOVET, en la obra antes citada, denuncia que la elección de los diputados provinciales por los partidos políticos las aleja de los ciudadanos y las convierte en botín para colocar eventuales y políticos que se quedan sin cargo. Por ello cree que deberían ser de elección directa, como propugna la Carta Europea de Autonomía Local. En cuanto a las tendencias en las reformas, advierte dos líneas, que propone unir para redefinir la provincia en España: de un lado la más política, que incide en la trasparencia y la legitimación, y otra más económica, preocupada por la simplificación y el ahorro.

25 Algunos ejemplos de la prensa, aireando el asunto a raíz del pacto PSOE-Ciudadanos: O. GRANADO y L. HEVIA, “Para qué sirve una diputación?”, eldiario.es, 23-2-2016; M. CALLEJA, “Diputaciones provinciales: quien gobierna, qué son, cuánto cuestan y para qué sirven”, ABC, 24-2-2016; D. LEMA et ALLI, “¿Cuánto cuestan las diputaciones provinciales”, El Mundo, 25-2-2016. 
El posterior acuerdo entre el PP y Ciudadanos, de agosto de 2016, que sí ha conseguido alumbrar un gobierno, contiene unos vagos compromisos de reformar las administraciones públicas (donde se incluyen las diputaciones), suprimir organismos innecesarios para evitar duplicidades y ahorrar gasto, pero asegurando la racionalidad e igualdad y sin poner en riesgo los servicios de quince millones de personas que viven en municipios menores de 20.00 habitantes $^{26}$.

Cuesta ver algún compromiso concreto y claro en este pacto; su mayor virtud es que se puede entender para hacer una cosa y la contraria. Es decir, también cosas buenas. Por ello, me parece interesante destacar que la composición del parlamento permite alcanzar pactos para acometer reformas productivas y necesarias, puesto que la LSRAL no contentó a nadie fuera del partido entonces gobernante y sus alambicadas formulaciones sobre los cambios competenciales en pos de la estabilidad presupuestaria y la eficiencia están quedando en agua de borrajas ${ }^{27}$.

\section{APUNTES DE LA JURISPRUDENCIA CONSTITUCIONAL RECIENTE}

En efecto, las Sentencias del Tribunal Constitucional 41/2016, de 3 marzo y 111/2016, de 9 junio (en adelante STC) (que resuelven los recursos de inconstitucionalidad interpuestos contra la LRSAL por la Asamblea de Extremadura y el gobierno de Andalucía respectivamente), rebajan mucho las pretensiones de esta Ley, pues las nuevas competencias que se le atribuyen a las diputaciones provinciales (contratación centralizada, administración electrónica y otras) no dejan de ser nuevas funciones de asistencia y cooperación voluntaria, sobre cuya decisión han de estar de acuerdo los municipios y las diputaciones.

Además, la STC 168/2016, de 6 octubre (en el recurso de inconstitucionalidad presentado por el gobierno del Principado de Asturias), insiste en que la coordinación por las diputaciones de los servicios obligatorios en municipios menores de 20.000 habitantes es también cooperación voluntaria, que solo podrá actuarse cuando ambas partes estén de acuerdo.

Y, en relación con las comarcas, recuerda que la disposición adicional sexta de la Ley en ningún caso impide que las comunidades autónomas puedan crear en el futuro comarcas para atribuirles ámbitos de gestión supramunicipal, aunque todavía no las hayan creado e incluso sin estar previstas en sus estatutos ${ }^{28}$.

26 Literalmente, el pacto PP-Ciudadanos reza así «La reforma de las Administraciones públicas, en particular, de las locales, para asegurar la eficacia y la eficiencia del servicio al interés general que garantice la igualdad básica de su disfrute por todos los españoles. Eliminar las duplicidades administrativas y los organismos innecesarios. En particular, promoveremos las reformas que garanticen una prestación eficiente y racional de las competencias y 36 servicios prestados por todos los niveles administrativos (Administración General del Estado, la Administración de las Comunidades Autónomas y los entes locales, incluidas las Diputaciones). El objetivo es generar ahorros que se destinarán, a medida que se vayan produciendo, a políticas sociales y medidas para la mejora de la competitividad. En todo caso, ninguna de las actuaciones pondrá en riesgo los servicios públicos que prestan estas administraciones a los ciudadanos y especialmente los que benefician a los 15.000 .000 de españoles que viven en municipios de menos de 20.000 habitantes.»

27 Han sido muchas las críticas obtenidas por esta Ley desde un punto de vista jurídico-constitucional. Entre las observaciones más atinadas están sin duda las del profesor Francisco VELASCO CABALLERO, por ejemplo, en su trabajo "El nuevo régimen local general y su aplicación diferenciada en las distintas comunidades autónomas”, Revista Catalana de Dret Public, núm. 48, 2014. El autor sostiene que, conforme a la jurisprudencia constitucional, las administraciones locales no pueden inaplicar con carácter general las leyes autonómicas a favor de la LRSAL.

28 Del FJ 4 que analiza esta impugnación, extraemos este significativo párrafo: «En tercer lugar, no puede perderse de vista que el régimen local no forma parte del contenido necesario del Estatuto de Autonomía (art. 147.2 CE) ni que, si el legislador estatutario optase por incluir dentro de él regulaciones a este respecto, debe limitarlas a unas líneas fundamentales o esenciales [SSTC 31/2010, FFJJ 36 y 37; 103/2013, FJ 4, y 41/2016, FJ 3 a)]. De modo que la organización comarcal, esté o no prevista en los Estatutos, puede ser objeto de legislación estrictamente autonómica. Tal legislación es, precisamente, la que puede establecer una regulación completa de la comarca, no limitada a las líneas fundamentales, aunque, naturalmente, respetando la legislación estatutaria y básica a este respecto, si es que existe. A su vez, hay que tener en cuenta que en este preciso ámbito la competencia básica estatal derivada del art.149.1.18. ${ }^{\text {a }} \mathrm{CE}$ es más estrecha y, por tanto, que la competencia estatutaria de las Comunidades Autónomas es más amplia: “las 'entidades locales no necesarias o contingentes', en general, y las de segundo grado (p. ej., comarcas), en particular”, “están dotadas de ‘un fuerte grado de interiorización autonómica', sin que les alcance directamente la garantía constitucional de la autonomía municipal (art. 140 CE), provincial (art. 141.2 CE) e insular (art. 141.4 CE)”; “entran en cuanto a su propia existencia en el ámbito de disponibilidad de las Comunidades Autónomas que dispongan de la correspondiente competencia” [STC 41/2016, FJ 5 , citando la STC 214/1989, FFJJ 4 b) y 15 a)].

Consecuentemente, puede interpretarse que la disposición adicional sexta de la Ley $27 / 2013$ supone que las previsiones de la reforma local de 2013 "se aplicarán respetando" toda "organización comarcal” estatutariamente prevista, sin por ello negar o perjudicar la que, no prevista en los Estatutos, pueda eventualmente llegar a instaurar cualquier Comunidad Autónoma al amparo de su competencia en orden a la creación y regulación de entidades locales de segundo grado. Téngase en cuenta a este respecto que la previsión controvertida está formulada en positivo, como cláusula de salvaguarda de las organizaciones comarcales estatutariamente previstas. No cabe interpretarla en negativo, como fuerte restricción a la autonomía de las Comunidades Autónomas traducida en la imposibilidad de ejercer sus amplias competencias en orden a la regulación y creación de entidades caracterizadas por "un fuerte grado de interiorización autonómica”.

Abona esta interpretación la circunstancia de que la Ley 27/2013 no haya modificado el art. 42 LBRL, conforme al cual "las Comunidades Autónomas, de acuerdo con lo dispuesto en sus respectivos Estatutos, podrán crear en su territorio comarcas u otras Entidades que agrupen varios Municipios, ...». 
Aún quedan otros seis recursos por resolverse, pero a la luz de esta jurisprudencia y del escaso alcance que está obteniendo la LRSAL, puede ser oportuno, estimo, que el legislador piense en las reformas pendientes, pues la situación está lejos de ser satisfactoria. Reformar la LBRL es la clave para mejorar la representatividad de las diputaciones, introducir los cambios orgánicos que necesitan, atribuirles responsabilidades competenciales claras y darles un régimen básico flexible que permita su adaptación a las realidades autonómicas.

\section{LA REALIDAD COMARCAL DE ESPAÑA}

En Europa se entiende la comarcalización como un mecanismo para solucionar la falta de recursos y la incapacidad de los municipios pequeños para ejercer sus competencias, concentrando así la gestión en unidades administrativas más amplias, con una economía de escala suficiente.

En España, el art. 42 LBRL define la comarca como un ente público supramunicipal que puede ser creado por las comunidades autónomas agrupando municipios. Son las leyes autonómicas las que deben precisar sus características, territorio, composición organizativa, competencias y funciones administrativas, recursos económicos, etc. Sí exige la LBRL que los órganos de gobierno representen a los ayuntamientos. Y no permite que priven de sus servicios obligatorios a los ayuntamientos ni de intervenir en las materias propias.

Al interpretar estos límites, ya la STC 214/1989, de 21 de diciembre (que resolvió los cuatro recursos de inconstitucionalidad acumulados contra la LBRL por parte de los gobiernos y parlamentos autonómicos gallegos y catalanes) admitió que la comarca es una entidad local con fuerte grado de interiorización autonómica, pero remarcando que el art 42 LBRL garantiza que las comunidades autónomas no puedan abolir los municipios al comarcalizar, mediante el desapoderamiento de la autonomía municipal. En otras palabras, que no pueden diluirse en la comarca, aunque si disminuir o acrecentar sus competencias

Por su parte, todos los estatutos de las comunidades pluriprovinciales prevén su existencia como entidad local supramunicipal y remiten a una futura ley para regularlas y crearlas. V. gr. el de Andalucía (art. 97 LO 2/2007, de 19 de marzo), el de Aragón (art. 83 LO 5/2007, de 20 de abril), el de Castilla-La Mancha (art. 29 LO 9/1982, de 10 de agosto), el de Cataluña (art. 92 LO 6/2006, de 19 de julio), el de Galicia (art. 40 LO 1/1981, de 6 de abril). Algunos estatutos además las contemplan como circunscripciones administrativas autonómicas. V. gr. el de Castilla y León (art. 46 LO 14/2007, de 30 de noviembre), el de la Comunidad Valenciana (art. 65 LO 5/1982, de 1 de julio) y el de Extremadura (art. 57 LO 1/2011, de 28 de enero).

Pero, hasta la fecha, solo se han implantado de modo general en Cataluña (Ley 6/1987, de 4 de abril, "de la Organización Comarcal de Cataluña", luego sustituida por el Decreto Legislativo 4/2003, de 4 de noviembre, "que aprueba el Texto refundido de la Ley de la organización comarcal de Cataluña") y en Aragón (Ley 10/1993, de 4 de noviembre, de Comarcalización de Aragón, sustituida luego por el Decreto Legislativo 1/2006, de 27 de diciembre, del Gobierno de Aragón, “que aprueba el texto refundido de la Ley de Comarcalización de Aragón”). Las resumiremos seguidamente.

En el resto de regiones pluriprovinciales no parece suscitar mayor entusiasmo, por ahora, ni ocupa apenas espacio en los estudios jurídicos, como es comprensible ante la falta de materia prima en forma de derecho positivo 29 .

\subsection{La organización comarcal de cataluña}

Culminada la comarcalización que se inició con la Ley de 1987, la organización comarcal de Cataluña está hoy regulada en el texto refundido aprobado por Decreto Legislativo 4/2003, que las configura como entidades locales supramunicipales encargadas de asegurar la prestación de competencias y servicios locales. Gozan de personalidad jurídica propia, capacidad y autonomía para cumplir sus fines.

La división comarcal del territorio catalán es completa, agrupando los 947 municipios en 42 comarcas, con sus correspondientes capitales.

29 Las obras publicadas apenas dedican una mención o un epígrafe a la figura. Así, el profesor ORTEGA ÁLVAREZ hace una exégesis del art. 29 del estatuto castellano-manchego a efectos de un posible desarrollo legal, en "Los entes locales en Castilla-La Mancha", capítulo del libro Derecho Local de Castilla-La Mancha, lustel, 2013, por mi dirigido. También hace lo propio BEATO ESPEJO en su libro Derecho Público de la Comunidad Autónoma de Extremadura, 1997, que se muestra favorable pero con muchas cautelas. Por su parte, SOSA WAGNER advierte que sería un error la proliferación de las comarcas en esa región si no se procede asimismo a reordenar el mapa municipal y a repensar el papel de las diputaciones, en el capítulo “Administración Local”, del libro Derecho Público de Castilla y León, dirigido por Ignacio SÁEZ HIDALGO, Lex Nova, 2008, pág. 747. 
Los escaños del Pleno del Consejo Comarcal se asignan a los partidos políticos en proporción a los votos obtenidos en las elecciones municipales. Al Consejo Comarcal corresponde el gobierno y la administración. También elige al presidente comarcal. Otros órganos son el Consejo de Alcaldes, de carácter consultivo, y la Comisión Especial de Cuentas, encargada de examinarlas.

Las competencias de las comarcas son genéricas, pues no se refieren a ningún ámbito material concreto. Son las que les atribuye esta Ley en materia de cooperación, asesoramiento y coordinación de los ayuntamientos, las que le atribuyan las leyes del Parlamento, las que les deleguen o les encarguen de gestionar la Generalidad, la diputación correspondiente, los municipios o las mancomunidades, que tienen que ir acompañadas de la transferencia de los recursos necesarios para ejercerlos.

Tampoco cuentan las comarcas con ninguna asignación de recursos concretos, aunque su financiación puede provenir en general de ingresos de derecho privado, tasas, contribuciones especiales, multas, participación en impuestos del Estado y de la Generalidad que puedan establecerse a su favor, subvenciones, créditos y las aportaciones de los municipios y de las diputaciones si asumen servicios suyos.

En suma, su configuración se asemeja mucho, solo que a menor escala, a las diputaciones provinciales, con las que se solapan y compiten, empero carecen de sus presupuestos financieros.

\subsection{La comarcalizacion de aragón ${ }^{30}$}

La comarcalización empezó con la citada Ley de 1993, para solucionar los desequilibrios de una región que cuenta con 1.300.000 habitantes, pero la mitad de ellos residentes en Zaragoza capital. El resto se reparte en 731 municipios. Además de la despoblación y la fragmentación, otro serio problema es el envejecimiento, pues el $60 \%$ de los municipios son terminales en términos sociológicos, esto es, que la mayoría de sus vecinos tienen más de 65 años. Como puede comprenderse, todos estos factores dificultan enormemente la prestación de los servicios públicos.

La creación de cada una de las 32 comarcas se hizo mediante las correspondientes leyes singulares, en un breve espacio de tiempo (entre 2001 y 2003), gracias a un importante consenso político ${ }^{31}$. Hoy la delimitación comarcal está consagrada por el Decreto Legislativo 2/2006, de 27 de diciembre, y su régimen jurídico contenido en el Decreto Legislativo 1/2006, de igual fecha.

La ciudad de Zaragoza es una más (33 en total), pero todavía está pendiente de constituirse formalmente, ya que, al parecer, su ayuntamiento apuesta más por un modelo metropolitano que rural, o por un estatuto de capitalidad.

Antes de resumir sus características, diremos que, como novedad, el Estatuto de Autonomía de 2007 convierte en necesaria y general la comarca como ente estructural de Aragón, junto con municipios y provincias.

La comarca se presenta en la Ley vigente como el medio más adecuado para subsanar las carencias municipales y elevar la calidad de vida de los ciudadanos, por su adaptación al territorio, por su cercanía y por su idoneidad para la organización de muchos servicios. Considera que las mancomunidades no han servido para implantar un modelo general en toda la región.

Define las comarcas como entidades locales territoriales, que tienen personalidad jurídica propia y gozan de capacidad y autonomía para el cumplimiento de sus fines.

El gobierno y la administración corresponde al Consejo Comarcal, cuyos escaños se asignan a los partidos en proporción a los votos de las elecciones municipales. El presidente es elegido por el citado Consejo. Otros órganos son la Comisión especial de Cuentas, integrada por todos los grupos representados y, en su caso, una Comisión de Gobierno.

Las comarcas pueden ejercer competencias en una larga lista de materias (urbanismo., transportes, ambiente., residuos, sanidad, enseñanza, ferias, bomberos, artesanía, deporte, cultura, etc...) cuyas funciones se especifican o bien se apuntan como posibles. A ellas pueden añadirse otras conforme a la legislación sectorial, siempre acompañada de la previsión de la correspondiente financiación.

30 La organización territorial de Aragón se estudia a fondo en el Tratado de Derecho Público Aragonés, dirigido por los profesores BERMEJO VERA y LÓPEZ RAMÓN, Thomson-Reuters, 2010. A los efectos de completar estos apuntes con exhaustiva información, merece la pena consultar el capítulo de SALANOVA ALCALDE, R., “Las comarcas”, págs. 789 a 808. También de Ramón SALANOVA,“La organización territorial de Aragón”, en el Derecho Público Aragonés, dirigido por Antonio EMBID IRUJO, publicado por El Justicia de Aragón en 2005.

31 El libro editado por Jorge INFANTE DÍAZ, Las Comarcas de Aragón: territorio y Futuro, Gobierno de Aragón, 2003, reúne un variado elenco de ponencias en las que se estudia el proceso de comarcalización desde diferentes disciplinas y no exclusivamente la político-administrativa. 
Podrán ejercer la iniciativa económica, participar en la elaboración de los programas de promoción agrarios, de las obras de infraestructura y de los servicios públicos básicos que en ellos se incluyan.

En todos los casos, la atribución y ejercicio se entienden sin perjuicio de las competencias del Estado, de la comunidad autónoma y de los municipios.

La comunidad autónoma podrá delegarles el ejercicio de sus competencias o encomendar la realización de actividades de carácter material, técnico o de servicios de su competencia a las comarcas. Igualmente pueden delegarles o encomendarles las diputaciones y los municipios.

Sin perjuicio de las competencias de las provincias, cada comarca podrá crear un servicio de cooperación y asistencia a los municipios que lo soliciten en materia jurídico-administrativa, económica y financiera y de obras y servicios.

Tras la constitución de los consejos comarcales, se constituyeron comisiones mixtas de transferencias para preparar las transferencias de funciones y servicios incluyendo los traspasos de medios personales y materiales. Las materias objeto de transferencia, en un primer bloque, han sido acción social, cultura, patrimonio cultural y tradiciones populares, deporte, juventud, promoción del turismo, recogida y tratamiento de basuras, protección civil y extinción de incendios.

Por otro lado, diversas leyes sectoriales aragonesas les asignan funciones concretas en materia de protección civil, vías pecuarias, protección de los consumidores, licencia ambiental y gestión forestal, entre otras.

En resumen, las comarcas aragonesas ejercen las competencias y funciones que les ha trasferido la comunidad autónoma y las municipales que antes gestionaban las mancomunidades, en ambos casos con los correspondientes dineros. De estos también han recibido competencias mediante convenios de encomienda. Pero, por lo que hemos leído, no han recibido nada de las diputaciones provinciales.

Prevé la Ley que la hacienda de las comarcas estará constituida por los ingresos procedentes de su patrimonio y demás de derecho privado, tasas y precios públicos, contribuciones especiales, multas, subvenciones, créditos, transferencias de la comunidad autónoma y de las provincias, y aportaciones de los municipios. Pero la realidad es que no pueden participar en los tributos ni de las trasferencias que el Estado asigna a ayuntamientos y diputaciones, por lo que su principal fuente de financiación está en lo que trasfiere la comunidad autónoma y aportan los municipios por los servicios que les prestan.

En suma, Aragón ha apostado por un nuevo tipo de administración local supramunicipal, las comarcas, para gestionar competencias y servicios trasferidos o delegados por la comunidad autónoma, con cargo a los presupuestos de la misma. Esto marca una diferencia notable respecto de Cataluña, donde la comarca tampoco es ámbito de los servicios periféricos de la Generalidad.

Algunos autores observan, sin embargo, que el tercer pilar de la comarcalización, que iba a ser un instrumento para el desarrollo económico endógeno del territorio, hasta ahora no se ha producido. Los que han impulsado nuevas actividades productivas en el territorio han sido los programas leader de la Unión Europea ${ }^{32}$.

Tampoco se ha logrado todavía una asunción de la identidad comarcal e identidad territorial.

Y otros han criticado que, por su pequeño tamaño, las comarcas no van a ser eficaces en la prestación de servicios y van a encarecerlos con gastos administrativos.

El punto en común de ambas comunidades autónomas es que las comarcas concurren con las provincias, a la que parece relegar a competencias básicas de asistencia y cooperación, pues su establecimiento no ha supuesto un replanteamiento de la diputaciones provinciales, ni ha afectado a sus competencias (con las que en algún caso se solapan) ni a su hacienda.

Quizás por ello su implantación no ha dado lugar a litigios ante el Tribunal Constitucional. Queda la duda de si es racional, eficiente en el gasto, simplifica la administración y aumenta la eficacia de los servicios a los ciudadanos $^{33}$. Cuando se considere suficientemente asentado este proceso merece ser objeto de una evaluación exhaustiva. Y también repensar si la rigidez del régimen legal básico impide o ayuda al conveniente ensamblaje institucional.

32 INFANTE, J., “Aproximación al modelo de comarcalización de Aragón. Una reflexión crítica”, Boletín de la Asociación de Geógrafos Españoles, núm. 52, 2010, págs. 59-80.

33 BARBERÁN ORTI, R., "La comarcalización de Aragón. Una valoración desde la economía del federalismo fiscal", Economía Aragonesa, núm. 21, 2003, págs. 50 a 86. 


\section{LAS VEGUERÍAS EN CATALUÑA}

\subsection{Origen estatutario y configuracion legal}

El estatuto de autonomía de Cataluña de 1979 preveía la organización en comarcas como el modelo propio. Así se inició la comarcalización en 1987, a la vez que se intentaba reducir y condicionar a las diputaciones (trasferencia de competencias no básicas, férrea coordinación, atraer la cooperación al plan único); que no obstante mantuvieron su importancia gracias a su presupuesto e implantación consolidada.

El borrador de nuevo Estatuto preveía sustituir las comarcas por las veguerías, pero el finalmente aprobado las mantiene en cohabitación con la veguería, a la que desplaza su atención ${ }^{34}$. Estas se han regulado legalmente sin redefinir el marco de las comarcas, ocasionando una nueva superposición. Tampoco es un tema pacífico a nivel político, no solo entre sus detractores pues suscita rivalidades internas a la hora de perfilar en detalle sus límites geográficos, capitalidades y otros aspectos ${ }^{35}$.

En efecto, el art. 2 del EAC 2006 dispone que Cataluña estructura su organización territorial en municipios, comarcas y veguerías. El art 90 define la veguería como el ámbito territorial específico para el ejercicio del gobierno intermunicipal de cooperación local y como la división territorial adoptada por la Generalidad para la organización de sus servicios. El art 91 dispone que el gobierno y la administración autónoma de la veguería corresponden al consejo de veguería, determina que los consejos de veguería sustituyen a las diputaciones provinciales y establece que la creación, modificación y supresión de las veguerías, así como el despliegue de su régimen jurídico deben ser regulados por ley del parlamento.

Por su parte, la Ley 30/2010, de 3 de agosto, “de veguerías”, regula la doble naturaleza de esta institución. De un lado, es ámbito territorial específico para el ejercicio del gobierno intermunicipal de cooperación local. Establece el régimen jurídico del órgano de gobierno y de administración, denominado consejo de veguería, de manera muy semejante a lo que dispone la LBRL para las diputaciones y sus competencias de cooperación y servicios supramunicipales.

De otro lado, la veguería es la nueva división territorial en la que se organizan los servicios de la Generalidad (demarcación veguerial), aunque la verdad es que dedica poca atención a este aspecto.

Son 7 las veguerías reconocidas en la Ley (Girona, Lleida, Alto Pirineo, Barcelona, Cataluña Central, Camp de Tarragona y Tierras del Ebro) más el Valle de Arán como entidad singular dentro del Alto Pirineo. Y regula la transición de las diputaciones provinciales a los nuevos consejos de veguería (bienes, personal, recursos, etc.), si bien condicionada a la modificación de la normativa estatal correspondiente y con amplios plazos de transición.

En virtud de la disposición transitoria primera, prevé la constitución de los consejos de veguería de Barcelona, Lleida, Girona y Tarragona, de acuerdo con los vigentes límites provinciales, tras la celebración de las elecciones municipales posteriores a la entrada en vigor de dicha ley. La disposición final primera concede una moratoria de 4 años para que la Generalidad se adapte a esta división periférica. Y la disposición final segunda establece que el Gobierno catalán debe presentar al Parlamento, para su propuesta a las Cortes Generales, las iniciativas legislativas necesarias para adecuar al ámbito territorial, incluidas las relativas al régimen electoral de la veguería y, así, completar el despliegue de la organización territorial.

No se determinan en dicha Ley los límites de cada veguería, ni el peso electoral que tendrán en el Parlamento de Cataluña; aspectos estos supeditados a una ley propia de división territorial y otra electoral, estrechamente ligadas. La idea, repito, era que inicialmente se constituyeran cuatro veguerías coincidentes con las actuales provincias de Barcelona, Lérida, Gerona y Tarragona. Posteriormente la veguería de Tarragona se dividirá en la veguería de las Tierras del Ebro y el Campo de Tarragona y después del cambio de los límites provinciales por parte de las Cortes Generales, se constituyeran las veguerías del Alto Pirineo y Valle de Arán y la de Cataluña Central.

\subsection{Incidencia de la STC 31/2010, 28 junio}

Vistas en perspectiva, se puede decir que las intervenciones del legislador catalán sobre el régimen local han generado una importante litigiosidad a nivel constitucional, empezando por la STC 32/1981, de 28 de julio, que de-

34 En el capítulo XI del libro de Mercé BARCELÓ y Joan VINTRÓ, Derecho Público de Cataluña, Atelier, 2008, los autores hacen un examen conjunto de las distintas entidades que componen la organización territorial catalana y sus relaciones.

35 Eva CLOTA, “El avispero de las veguerías. El mapa genera conflictos en Tarragona, Cataluña central y Penedès”. http://elpais.com/ diario/2009/12/29/catalunya/1262052445_850215.html. 
claró la inconstitucionalidad de una buena parte de la Ley 6/1980, de 17 de diciembre, "de transferencia urgente y plena de las Diputaciones Catalanas a la Generalidad" ${ }^{36}$.

En este contexto, la STC 31/2010, de 28 de junio, dedica el FJ 91 a analizar lo previsto en el art. 91 del EAC 2006 sobre las veguerías. En síntesis, determina que esta regulación debe acomodarse a las bases estatales. Entiende la Sentencia que la omisión de la provincia en el Estatuto únicamente significa que éste no entra más que en la organización territorial propia de Cataluña, pero que ello no supone que cuestione la estatal. Constata que la veguería es una entidad local propia y distinta de la provincia. Y admite que puedan sustituir en su denominación a las diputaciones. Sin embargo, considera que cambiar la composición, el sistema de elección y demás elementos de las mismas corresponde al Estado. En suma, que solo pueden sustituir a las diputaciones cuando sus límites coincidan, lo que ha de hacerse por una ley orgánica. Por todo lo cual, el Tribunal falla que los apartados 3 y 4 del art. 91 EAC 2006 no son inconstitucionales, pero siempre que se interpreten en los términos establecidos en el fundamento jurídico 41 de la Sentencia.

A pesar de ello, Tomás FONT reclama una relectura de la jurisprudencia constitucional; en particular de esta Sentencia. A su juicio, no se puede impedir la competencia básica para fijar el mínimo común denominador, pero el Estado tampoco reducir la competencia autonómica. Se fija en la STC 132/2012 sobre consejos insulares baleares, que no aprecia que la ley balear atente a la autonomía local, pues el autogobierno isleño se concreta en corporaciones representativas y el estatuto los tiene como parte del sistema institucional de la comunidad, con una amplia regulación sustantiva de su composición, elección, organización, etc. Es el «anclaje estatutario» lo que permite al Tribunal una lectura conforme porque el propio estatuto es un hecho diferencial -no solo el insular- que justifica una aplicación no homogénea de la LBRL. Desde luego, su elección por sufragio directo no vulnera el carácter representativo del consejo insular como elemento constitutivo de la autonomía local ${ }^{37}$.

Una visión diferente es la de MUÑOZ MACHADO, para quien debería distinguirse la provincia como demarcación estatal y la provincia como corporación local; de modo que, al ser el régimen local un asunto intracomunitario, lo cree conforme a la Constitución ya que el Estatuto de Cataluña no consagra la provincia y prevé sustituirla por otro ente que sea la división periférica autonómica y entidad local supramunicipal, sustituyendo a la diputación. Para este autor, esto no es un cambio sustancial y cabe en las potestades autoorganizatorias y sobre régimen local de la comunidad autónoma; sin que ello impida que el Estado la siga usando como demarcación periférica y electoral propia ${ }^{38}$.

En todo caso, como señala el profesor Antoni BAYONA, de la situación creada surgen serios problemas ${ }^{39}$. Por una parte, una inflación de niveles administrativos: municipio, comarca, veguería, diputación, etc. Por otra, que paradójicamente la organización de los servicios periféricos de la Generalidad se supedita a la demarcación provincial, cuya modificación está reservada a ley orgánica, pues no cabe estatutariamente que las veguerías sean unas a efectos locales y otras como órganos periféricos de la comunidad autónoma.

Aunque la STC 31/2010 no se refleja en la Ley 30/2010, de 3 de agosto, de veguerías, que es posterior, sí que propició que fuera modificada por la Ley 4/2011, de 8 de junio. Según su preámbulo, la Ley pospone la constitución de las veguerías a causa de la crisis económica que sufre Cataluña, y la necesidad de adaptar previamente el marco legal estatal aplicable.

De momento las veguerías han quedado aparcadas. Puede que a expensas del desenlace del proceso soberanista o de una reforma de la LBRL y de la legislación orgánica atiente. De facto, no obstante, los servicios periféricos de la Generalidad sí se están acomodando a la nueva división territorial en ciernes.

36 Según Catalina ESCUIN PALOP (“Algunas reflexiones sobre la Administración local”, en el libro coordinado por BAÑO LEÓN, Memorial para la reforma del Estado, tomo II, págs. 1981 y ss.), los intentos de la Generalidad de hacerlas desaparecer han sido abortados por Sentencias de Tribunal Constitucional. Pero no solo en esta comunidad. También lo intentó la Comunidad Valenciana con Ley 2/1983, de 4 de octubre, "que declara de interés general para la Comunidad Valenciana determinadas funciones propias de las Diputaciones Provinciales" -convalidada por el Tribunal Constitucional-, si bien la Ley 8/2010, de 23 de junio, “de Régimen Local de la Comunitat Valenciana” eliminó después el listado de materias que la Generalidad iba a coordinar.

37 FONT I LLOVET, op. cit., págs. 1940 y ss. Cierto que el voto particular de los magistrados Adela Asua y Luis Ortega discrepa, pues creen que las especialidades estatutarias no pueden alterar las previsiones de la legislación básica. Pero, como indica el profesor FONT, la STC 31/2010 no dijo que el estatuto catalán trasgrediera la competencia estatal, ya que no impedía su ejercicio en el sentido de agotar la materia.

38 MUÑOZ MACHADO, S., op. cit., pág. 159 y ss.

39 BAYONA I ROCAMORA, A., "La Ley de veguerías y la STC 31/2010", Anuario del Gobierno Local 2010, Fundación Democracia y Gobierno Local, págs. 203 y ss. El mismo autor analiza la incidencia sobre el régimen local en el número especial que a la Sentencia del Tribunal Constitucional sobre el Estatuto dedicó la Revista Catalana de Dret Public. 


\section{PROPUESTAS FINALES}

La mayoría de los juristas que se acercan a este debate se hace eco de los problemas que critica la gente y denuncian algunos políticos, añadiendo algunos otros como la falta de racionalidad, la complejidad y la oscuridad competencial generada. Las reformas hasta ahora han consistido en añadir nuevas administraciones, más que corregir las existentes, sin sustituirlas ni siquiera reducirlas. En general, predomina la insatisfacción y, aunque no pueda dejar de valorarse el rol de las diputaciones como paraguas del poder local o que la provincia asegura la presencia del Estado en el territorio, es un clamor la petición de reforma de las diputaciones de régimen común, con independencia de la interiorización por las comunidades autónomas o sin ella.

Otro problema que yo resaltaría es la falta de adaptabilidad del marco legal básico a la diversidad del modelo poblacional español. Pondremos algunos ejemplos. De los 8.000 municipios, el 96\% son menores de $20.000 \mathrm{~h}$. Solo en Castilla y León hay 2.233 municipios. La provincia de Burgos tiene 371 municipios y Salamanca 362, mientras que Pontevedra sólo 62 y Cádiz 44. Andalucía tiene 81 municipios mayores de 20.000 habitantes y Cataluña 69, mientras que Extremadura 7 y Aragón sólo 4. Quiere decirse que en España hay de todo, provincias y comunidades autónomas con poca población y muchos ayuntamientos y al revés. Esta realidad tiene que ser entendida y asumida para enfriar el debate y evitar que lo domine el apasionamiento nacionalista.

En mi opinión, no se puede negar la conveniencia de una reforma del título VIII de la Constitución. La jurisprudencia constitucional en materia local es ejemplo de lo alambicado del sistema al que hemos llegado, abocado a una complejidad creciente y a una litigiosidad constante. Pero, mientras tanto, tampoco se pueden dejar de acometer reformas legales, por más que resolver este debate parezca «la cuadratura del círculo». Ese problema matemático, en apariencia insoluble, en realidad lo era para los griegos clásicos, que solo usaban la regla y el compás. Pero dejó de serlo en cuanto se descubrió la constante «pi».

En nuestro caso, la cuadratura del círculo pasa por la reforma de las diputaciones en la LBRL, puesto que, dentro del bloque de la constitucionalidad, la jurisprudencia antepone sus dictados a los estatutos de autonomía. Esta reforma ha de asumir la realidad diversa del modelo poblacional español, como se ha hecho con los ayuntamientos.

Entiendo que buscar soluciones «ad hoc» no es forzosamente un drama. En ese sentido, conviene separar lo que es la provincia como circunscripción electoral general y como división periférica del Estado (arts. 68.2 y 137 CE), de lo que es una administración supramunicipal (art. 141.1 CE) y la demarcación periférica de las comunidades autónomas (art. 148.1.1 $1^{\mathrm{a}} \mathrm{CE}$ ).

La jurisprudencia constitucional admite que pueda haber variantes cuando hay un hecho diferencial estatutario que tiene su tratamiento en la LBRL, como sucede con los cabildos y mancomunidades insulares. Igualmente, las Sentencias repiten que las competencias locales pueden cambiar y las formas de gobierno adaptarse. En esa línea, la reforma debería permitir, por no decir exigir, que la creación de una nueva entidad local supramunicipal ha de conllevar la clarificación y redistribución de las competencias de los entes existentes. Es esta una máxima, evitar la proliferación de entidades que se superponen sin que antes se clarifiquen y redistribuyan sus competencias en la que insisten muchos autores, como SOSA WAGNER, pues es ampliamente compartida.

Los cambios que, en relación con las veguerías, el Tribunal Constitucional reserva al Estado, no suponen en sí mismas ningún cataclismo para España. Que en lugar de 4 las provincias catalanas fuesen 7 veguerías conlleva, eso sí, redefinir su territorio y adecuar el número de escaños que les corresponderían en el Congreso y en Senado. Con los archipiélagos, Ceuta o Melilla ya sucede. Y, cuando se conoce en detalle, su tamaño en población y superficie no sería menor que el de otras muchas provincias que ya existen ${ }^{40}$.

Sería paradójico, pero no por ello menos positivo, que la comarcalización de Aragón y la implantación de las veguerías en Cataluña lograsen uno de los principales objetivos que pretendió el Informe de la Comisión de Expertos sobre Autonomías de 1981, evitar la proliferación de entes administrativos haciendo del nivel supramunicipal la instancia de confluencia entre la administración local y la descentralización autonómica ${ }^{41}$. Pero ello, como ya se ha dicho, requiere reordenar competencias, haciendas y demás ingredientes que hoy definen las diputaciones, comarcas y veguerías. Dicho esto, es obvio que, por más estudios doctrinales que se presenten, la solución tiene que ser política.

40 Algunos datos comparativos. Sobre el mapa, el tamaño de las veguerías oscila entre los 6.000 km² del Alto Pirineo y Arán y los 3.000 $\mathrm{km}^{2}$ del Campo de Tarragona. Ergo, todas las veguerías resultantes tendrían mayor tamaño que Tenerife, Álava, Vizcaya o Guipúzcoa. El número de habitantes, la mayoría supera a La Rioja y solo la del Alto Pirineo y Valle de Arán tendría menos población que Soria.

41 El Informe de la Comisión de Expertos sobre Autonomías, presidida por E. GARCIA DE ENTERRÍA, fue publicado por el Centro de Estudios Constitucionales en mayo de 1981, y se refería a la posición de las diputaciones provinciales en las páginas 26 y 27. Su posición quizá pueda resumirse en esta frase: «Es, pues, el modelo vasco, matizando en lo necesario para despojarlo de sus propias tradiciones, el que, a juicio de la Comisión, debe reproducirse en todas la Comunidades autónomas pluriprovinciales que se constituyan». 